\section{EACS}

How to cite this article: Barros et al. Smartwatch, oxygen saturation, and COVID-19: Trustworthy? ABCS Health Sci. 2021;46:e021101. https://doi.org/10.7322/ abcshs.2020228.1681

Corresponding author: Gabriel Martins de Barros - Centro de Ciências da Saúde, Universidade Federal do Piauí - Campus Ministro Petrônio Portela - Iningá - CEP: 64049-550 - Teresina (PI), Brazil -

Email: gabrielbmartins97@gmail.com

Declaration of interests: nothing to declare

This is an open access article distributed under the terms of the Creative Commons Attribution License

(C) 2021 Barros et al

\title{
Smartwatch, oxygen saturation, and COVID-19: Trustworthy?
}

\author{
Gabriel Martins de Barros ${ }^{1}$, Gabrielly Martins de Barros², Monaliza Sousa dos Anjos ${ }^{1}$, \\ João Batista Raposo Mazullo Filho ${ }^{3}$ \\ ${ }^{1}$ Centro de Ciências da Saúde, Universidade Federal do Piauí (UFPI) - Teresina (PI), Brazil. \\ ${ }^{2}$ Departamento de Nutrição, Faculdade Maurício de Nassau (Uninassau) - Teresina (PI), Brazil. \\ ${ }^{3}$ Departamento de Fisioterapia Cardiorrespiratória, Universidade Tuiuti do Paraná (UTP) - Curitiba \\ (PR), Brazil.
}

In the current COVID-19 pandemic, caused by the new coronavirus (SARS-CoV 2), two types of patients presented with moderate to severe hypoxia. One group of patients was distressed, panting with difficulty in breathing, and required intubation. However, the pathophysiology of the other group of patients did not resemble any preexisting patterns. These patients had low oxygen saturation but did not have significant breathing difficulties and looked clinically well ${ }^{1}$.

As many of these patients were markedly tachypneic and had hypoxemia that did not respond to supplemental oxygen, most were intubated early ${ }^{1}$. It is possible that the SARS-CoV-2 virus has a specific action on the receptors involved in chemosensitivity to oxygen ${ }^{2}$.

In this context, $\mathrm{SpO}_{2}$ monitoring is essential for better outcomes in patients with COVID-19, characterized by being a marker of early intubation. Outside the hospital setting, infected or suspected individuals are advised to rest at home to reduce contagion. This will prevent overwhelming the health system in some places in the world where the pandemic persists or is entering a second wave, as in Europe and the United States.

In these symptomatic patients at home, $\mathrm{SpO}_{2}$ monitoring can be important from the beginning, to inform patients regarding the best time to seek medical services. The availability and accessibility of smartwatches allow the measurement of $\mathrm{SpO}_{2}$ at home. However, many of these vital sign measurement devices have not been formally studied in a clinical setting ${ }^{3}$.

Literature regarding the validation and reliability of smartwatches or wearable technologies for measuring vital signs are scarce, even after some positive aspects as verified in the study by Lauterbach et $\mathrm{al.}^{4}$ in which the Garmin fēnix ${ }^{\circledR} 5 \mathrm{X}$ Plus watch showed positive results for $\mathrm{SpO}_{2}$ measurement. The measurements were analyzed and compared with measurements made using a standard pulse oximeter in 13 women and 10 men. The measurements were made using a personalized environmental chamber, while the fraction of inspired oxygen was adjusted to simulate altitudes from 275 to $3700 \mathrm{~m}$. The results showed that the smartwatch exhibited minimal overestimation of $\mathrm{SpO}_{2}$ and minimal underestimation of heart rate during exposure to simulated altitude, except at $3700 \mathrm{~m}$ simulated altitude, which reveals that the device may be viable for measuring vital signs.

In an Everlast TR $10^{\circledR}$ analytical survey, despite not measuring $\mathrm{SpO}_{2}$, the study results showed that this smartwatch was not accurate enough to be used as a vital sign measurement device ${ }^{3}$. 
Starting with the Apple Watch Series $4^{\circledR}$, market leaders got electrocardiogram features approved by the Food and Drug Administration (FDA) of the United States of America. These devices allow for safe monitoring of heart rhythm, frequency, and QT interval, and can provide a distinct advantage in managing patients with a variety of pathologies, including SARS-CoV-2 infection ${ }^{5}$. In addition to what has been reported by patients with COPD, individuals prefer to use smartwatches instead of other devices for continuous monitoring because of the design of the wearable device, which is reportedly elegant, comfortable, and suitable for long-term use ${ }^{6}$.

However, the Apple Watch Series $6^{\circledR}$ version, capable of measuring $\mathrm{SpO}_{2}$, is not approved by government agencies for this function. Therefore, the hardware to measure blood oxygen levels cannot be operated by the watch user, who therefore cannot measure their vital signs.

Measuring $\mathrm{SpO}_{2}$ on the wrist presents several challenges. Data capturing on the wrist can be used only for specific areas, such as the radial artery; therefore, most areas in the wrist region are not available for monitoring. In addition, a slight change in position of the measurement site significantly affects the result ${ }^{7}$.
The first FDA-approved health monitor with a pulse sensor was the Oxitone $1000 \mathrm{M}^{8}$. In this device, the sensor is located on the upper part of the ulnar wrist bone and not on the tip of a bulky finger. Recently, very few of the Fitbit ${ }^{\circledR}$ models have also received FDA approval.

It is worth mentioning that knowledge about pulse oximetry in the general population is low, and further limited among health professionals. Some professionals do not know about the limitations of conventional pulse oximeters used in a hospital environment and the relevant physiological principles regarding the use of these devices ${ }^{9,10}$. From this perspective, even health professionals may probably lack skills of measuring $\mathrm{SpO}_{2}$ with wearable technologies. Therefore, users without any training regarding the use of these new wearable devices should execute caution.

Special care is needed with regard to the data provided by smartwatches, especially during the COVID-19 pandemic. Most watches have not been approved by regulatory agencies, in addition to a lack of validation studies. Eventually, wearable technologies will be able to measure all human physiological parameters accurately and quickly, regardless of manual movement. However, more reliable studies are needed to validate these wearable technologies.

\section{REFERENCES}

1. Caputo ND, Strayer RJ, Levitan R. Early Self-Proning in Awake, Non-intubated Patients in the Emergency Department: A Single ED's Experience During the COVID-19 Pandemic. Acad Emerg Med. 2020;27(5):375-8. https://doi.org/10.1111/acem.13994

2. Tobin MJ, Laghi F, Jubran A. Why COVID-19 Silent Hypoxemia Is Baffling to Physicians. Am J Respir Crit Care Med 2020;202(3):356-60. https://doi.org/10.1164/rccm.202006-2157CP

3. Hahnen C, Freeman CG, Haldar N, Hamati JN, Bard DM, Murali V, et al. Accuracy of vital signs measurements by a smartwatch and a portable health device: Validation study. JMIR Mhealth Uhealth 2020;8(2):e16811. https://doi.org/10.2196/16811

4. Lauterbach CJ, Romano PA, Greisler LA, Brindle RA, Ford KR, Kuennen MR. Accuracy and Reliability of Commercial Wrist-Worn Pulse Oximeter During Normobaric Hypoxia Exposure Under Resting Conditions. Res Q Exerc Sport. 2020;1-10. https://doi.org/10.1080/02701367.2020.1759768

5. Mishra T, Wang M, Metwally AA, Bogu GK, Brooks AW, Bahmani A, et al. Pre-symptomatic detection of COVID-19 from smartwatch data. Nat Biomed Eng. 2020;4(12):1208-20. https://doi.org/10.1038/s41551-020-00640-6
6. Wu RC, Ginsburg S, Son T, Gershon AS. Using wearables and selfmanagement apps in patients with COPD: a qualitative study. ERJ Open Res. 2019;5(3):36-2019. https://10.1183/23120541.00036-2019

7. Lee $\mathrm{H}, \mathrm{Ko} \mathrm{H}$, Lee J. Reflectance pulse oximetry: Practical issues and limitations. ICT Express 2016;2(4):195-8. https://doi.org/10.1016/j.icte.2016.10.004

8. Oxitone Medical Follow-up Made Effortless. Oxitone 1000M: World's First FDA-cleared wrist-sensor pulse oximetry monitor. [Cited 2020 Dec 12]. Available from: https://www.oxitone.com/ oxitone-1000m/

9. Elliott M, Tate R, Page K. Do clinicians know how to use pulse oximetry? A literature review and clinical implications. Aust Crit Care. 2006;19(4):139-44 https://doi.org/10.1016/S1036-7314(06)80027-5

10. Milutinović D, Repić G, Aranđelović B. Clinical nurses' knowledge level on pulse oximetry: A descriptive multi-centre study. Intensive Crit Care Nurs. 2016;37:19-26. https://doi.org/10.1016/j.iccn.2016.05.006 